\title{
Simulation on Potassium Ion Concentration Profile of Engineered Stress Profile Glass by FDTD Method
}

\author{
ZHENG Guo-Yuan $^{1,2}$, LI Jia-Cheng ${ }^{1}$, SONG Li-Xin ${ }^{1}$, ZHANG Tao ${ }^{1}$ \\ (1. Key Laboratory of Inorganic Coating Materials CAS, Shanghai Institute of Ceramics, Chinese Academy of Science, Shang- \\ hai 200050, China; 2. University of Chinese Academy of Science, Beijing 100049, China)
}

\begin{abstract}
Strength of Engineered Stress Profile glass has been proved narrowly distributed owing to its particular exchanged ion profile. In order to predict the $\mathrm{K}^{+}$concentration profile, Finite-Difference Time-Domain method was introduced to simulate the diffusion processes. Simulation procedures were conducted based on detected diffusion coefficients, surface concentrations, and ion profile subjected to single step ion exchange. The calculated results show a reasonable agreement with the experimental measurements (Energy Dispersive Spectroscopy). According to the simulation results, the relation between $\mathrm{K}^{+}$profile and strength performance were interpreted.
\end{abstract}

Key words: ion-exchange; Engineered Stress Profile glass; Finite-Difference Time-Domain method; strength

The strength of brittle materials, such as inorganic glass and ceramics, always exhibits great dispersity. This phenomenon is caused by various flaws types, flaw positions and extension rates of flaws ${ }^{[1-2]}$. Naturally, strength of brittle materials is typically characterized by using statistical distribution functions (Weibull statistics) ${ }^{[3-4]}$.

Several approaches have been taken to reduce the strength variability of brittle materials. For example, Rao et $a l^{[5]}$ reported that laminates composed of alternate layers with different coefficients of thermal expansion could yield threshold strength. The structures have periodic stress profile, within which cracks originate from the tensile layers and are sandwiched between the adjacent compressive layers. By analogy, Fillery and Lange fabricated such a structure by bonding ion-exchanged glass bars together ${ }^{[6]}$. Furthermore, this conception was extended to a 3-D architecture ${ }^{[7-8]}$. Ion exchange is an effective way to strengthen glass by introducing surface compression $^{[9-10]}$. Tandon and Green were the first to introduce a subsurface maximum residual compressive stress to glass by a two-step ion exchange (termed ESP glass, Engineered Stress Profile Glass), i.e. immersed in $\mathrm{KNO}_{3}$ bath for a long time to exchange $\mathrm{Na}^{+}$for $\mathrm{K}^{+}$, and followed by short time process in salt composed by $\mathrm{KNO}_{3}$ and $\mathrm{NaNO}_{3}$ to back exchange part of the $\mathrm{K}^{+[11-14]}$. By this procedure, the position of the maximum stress value was shifted from the surface to subsurface. Crack propagations are suppressed by the subsurface compressive stress, and the glass is not broken until the applied tensile stress exceeds a specific value decided by the stress profile. This performance was demonstrated theoretically that the presence of the R-curve leads to crack stability under the action of applied load and to strength insensitivity to the initial flaw size ${ }^{[13,15-18]}$. The strength variability of ESP glass can be sharply decreased with Weibull modulus even exceeding $60^{[10]}$. Compared with the periodic structures put forward by Rao et al., the procession of ESP glass has the advantage of massive production and simple technology.

The residual stress profile of ESP glass is established based on the ion concentration distribution within the surface layer (about $100 \mu \mathrm{m}$ ), despite the stress relaxation $^{[19-20]}$. The key to produce ESP glass of low strength variability is to obtain a $\mathrm{K}^{+}$profile with a proper peak location and an enough sharp positive gradient in the rising part ${ }^{[21]}$. However, many experiments of various conditions and measurements have to be done to find out the optimal parameters. Therefore, it will make significance to develop an efficient way to predict the ion profile under various conditions.

The major aim of this paper is to establish a methodology to predict the ion profile within glass after the secondstep ion-exchange. With FDTD method (Finite-Difference Time-Domain method), the numerical procedure of the diffusion process can be conducted. Therefore, the distribution of $\mathrm{K}^{+}$can be accurately calculated based on certain conditions: time, boundary conditions, initial conditions and the diffusion coefficients. 


\section{Experimental and theoretical approach}

\subsection{Sample preparation}

The glass used in this research is soda aluminosilicate glass (Corning2320) which is 1-mm thick. The glass was cut into $10 \mathrm{~mm} \times 6 \mathrm{~mm} \times 1 \mathrm{~mm}$ bars which were suitable for electron micro-analysis by an automatic dicing saw (DISCO, DAD320, JAPAN), along with samples $40 \mathrm{~mm}$ $\times 5 \mathrm{~mm} \times 1 \mathrm{~mm}$ for the strength test. Afterwards, the edges of the samples were carefully polished to a mirror finish.

Salt of the first-step ion-exchange (denoted as Salt 1) is composed of $97 \mathrm{wt} \% \mathrm{KNO}_{3}(\mathrm{AR}, 99.0 \%$, Aladdin) and $3 w t \%$ auxiliary chemicals $\left(\mathrm{K}_{2} \mathrm{CO}_{3}\right.$ (AR, 99.0\%, Aladdin), $\mathrm{KOH}(\mathrm{GR}, 95.0 \%$, Aladdin), and diatomite (average particle size: $25.4 \mu \mathrm{m}$, Aladdin). Salt of the second-step ion-exchange (denoted as Salt 2) is composed of 70wt\% $\mathrm{KNO}_{3}$ and 30wt\% $\mathrm{NaNO}_{3}$ (GR, 99.0\%, Aladdin). The ion-exchange procedure was performed using a semiautomatic furnace (XFT300, Suzhou, China) which allowed simultaneous treatment of 60 samples that were suspended by a stainless-steel frame in a $10 \mathrm{~L}$ liquid salt bath. Before being immersed in the molten salts, the samples were firstly heated to $350^{\circ} \mathrm{C}$ and then preserved for $10 \mathrm{~min}$ in an electric furnace. After each step of ion exchange, the glass was immediately transferred into the furnace at $350^{\circ} \mathrm{C}$ then slowly cooled to room temperature. Treatments of the samples are shown in Table 1.

\subsection{Strength Measurement}

The strength of the glass bars with the size of $40 \mathrm{~mm}$ $\times 5 \mathrm{~mm} \times 1 \mathrm{~mm}$ was measured by three points bending test with a universal material testing machine (H10KT, TINIUS OLSEN, America) whose actuator speed was set at $5 \mathrm{~mm} / \mathrm{min}$. Those bars were assumed as an ideal rectangle, and their sizes including length, width and height were carefully measured before the bending test. 16 pieces of glass bars, as a group, for the sample P0,

Table 1 The various treatments of the samples

\begin{tabular}{ccc}
\hline Batch Code & $\begin{array}{c}\text { First-step } \\
\text { process (Salt 1) }\end{array}$ & $\begin{array}{c}\text { Second-step } \\
\text { process (Salt 2) }\end{array}$ \\
\hline P0 & - & - \\
P1 & $450^{\circ} \mathrm{C}, 42 \mathrm{~h}$ & $400^{\circ} \mathrm{C}, 15 \mathrm{~min}$ \\
P2 & $450^{\circ} \mathrm{C}, 42 \mathrm{~h}$ & $400^{\circ} \mathrm{C}, 30 \mathrm{~min}$ \\
P3 & $450^{\circ} \mathrm{C}, 42 \mathrm{~h}$ & $400^{\circ} \mathrm{C}, 1 \mathrm{~h}$ \\
P4 & $450^{\circ} \mathrm{C}, 42 \mathrm{~h}$ & $400^{\circ} \mathrm{C}, 2 \mathrm{~h}$ \\
D1 & $450^{\circ} \mathrm{C}, 42 \mathrm{~h}$ & - \\
D2 & - & $400^{\circ} \mathrm{C}, 12 \mathrm{~h}$ \\
D3 & - & $350^{\circ} \mathrm{C}, 12 \mathrm{~h}$ \\
\hline
\end{tabular}

P1, P2, P3, P4 were tested and recorded.

\subsection{Potassium ion profile measurement and surface concentration detection}

The samples (P0-P4, D1-D3) with the size of $10 \mathrm{~mm} \times$ $6 \mathrm{~mm} \times 1 \mathrm{~mm}$, one of each code, were face-to-face stuck to a pile using molten rosin. The glass pile was then immersed in $41 \mathrm{wt} \% \mathrm{HF}$ aqueous solution for $2 \mathrm{~h}$ to have the lateral surface layers corroded entirely (in Fig.1). Afterward, the pile was cleaned with deionized water, and then the corroded faces were carefully polished to a mirror finish. The $\mathrm{K}^{+}$profile was detected by a scanning electron microscope (SEM) and an energy dispersive spectrometer (EDS) with the line-scanning mode. The surface concentration of $\mathrm{K}^{+}$was also determined by averaging the composition value of three random points on the ion-exchanged faces of each sample. All samples were tested in the same batch and under the same physical environment (10 kV, $30 \mathrm{~A})$.

\subsection{Numerical procedure of the diffusion proc- ess by FDTD method}

In the current study, $\mathrm{K}^{+}$at same depth is considered homogeneously distributed. Thus diffusion process of the $\mathrm{K}^{+}$profile along depth can be simplified as a onedimensional problem. Numerical procedures for diffusion process have been solved by Shidfar, et al. using FDTD method $^{[22-23]}$. In the following study, $\Delta t>0$ and $\Delta x>0$ are defined as a step length on the $t$ coordinate $\{0=$ $\left.t_{0}<t_{1}<\cdots<t_{i}<\cdots<t_{M}=T\right\}$ and $x$ coordinate $\left\{0=x_{0}<\right.$ $\left.x_{1}<\cdots<x_{j}<\cdots<x_{N}=L\right\}$ where $i, j$ denote the indexes of time and depth.

For diffusion equation:

$$
\frac{\partial C(x, t)}{\partial t}=\frac{\partial}{\partial x}\left(D(x) \frac{\partial C(x, t)}{\partial x}\right)
$$

Inside the glass, the diffusion process can be discretized and interpreted as follows:

$$
\begin{aligned}
& 1<j<N, \\
& \frac{C_{i+1, j}-C_{i, j}}{\Delta t}= \\
& \frac{1}{\Delta^{2} x}\left(\frac{\frac{D\left(C_{i, j}\right)+D\left(C_{i, j+1}\right)}{2}\left(C_{i, j+1}-C_{i, j}\right)+}{\frac{D\left(C_{i, j}\right)+D\left(C_{i, j-1}\right)}{2}\left(C_{i, j-1}-C_{i, j}\right)}\right)
\end{aligned}
$$

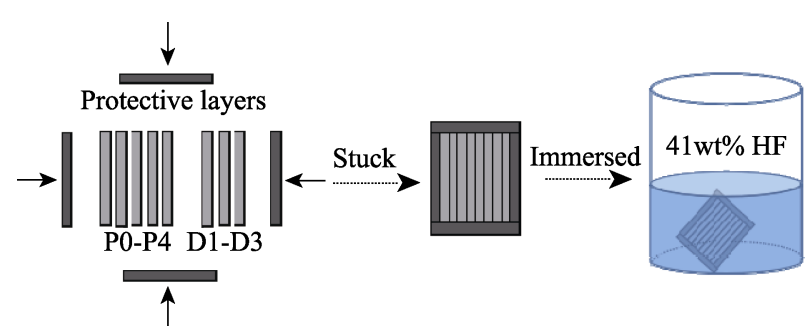

Fig. 1 HF treatment for the glass samples 
For glass immersed in molten salt, it is assumed that the surface concentration of potassium keeps constant once the diffusion balance is established ${ }^{[22]}$. Thus the boundary condition can be simply described as:

$$
C_{1}=C_{N}=C_{s}
$$

Here $C_{s}$ is the the surface concentration of $\mathrm{K}^{+}$.

\section{Results and Discussion}

The simulation was performed based on the following three types of data.

1) The $\mathrm{K}^{+}$profile after the first-step ion-exchange (initial condition).

2) The surface concentration of samples immersed in Salt 2 at $400^{\circ} \mathrm{C}$ (boundary condition).

3) The diffusion coefficient of $\mathrm{K}^{+}$within the glass at $400^{\circ} \mathrm{C}$.

\subsection{Initial condition and boundary condition}

The $\mathrm{K}^{+}$profile along the direction of depth after the first-step ion-exchange (D1) is plotted in Fig. 2. The concentration value was normalized in order to eliminate the absolute error induced by the measurements. The concentration profile was fitted by a polynomial approach and transferred to a computer. Here five-order polynomials are chosen to describe the fluctuation of the information properly.

$$
\begin{gathered}
F(x)=0.97467-9.72 \times 10^{-3} x-2.98015 \times 10^{-4} x^{2}+5.63154 \times \\
10^{-6} x^{3}-3.32571 \times 10^{-8} x^{4}+6.61518 \times 10^{-11} x^{5}
\end{gathered}
$$

As observed in Fig. 2, the diffusion depth is about $90 \mu \mathrm{m}$ after $42 \mathrm{~h}$ immersion in Salt 1 at $450^{\circ} \mathrm{C}$. This range is much deeper than that of most cracks and crack-like flaws which are typically in the range of 20-50 $\mu \mathrm{m}^{[16]}$.

Define $\Delta L=120 \mu \mathrm{m}$ and $\Delta x=0.1 \mu \mathrm{m}$ as the space range and the step length of the space. The initial condition was assigned by the mathematical polynomial equation above.

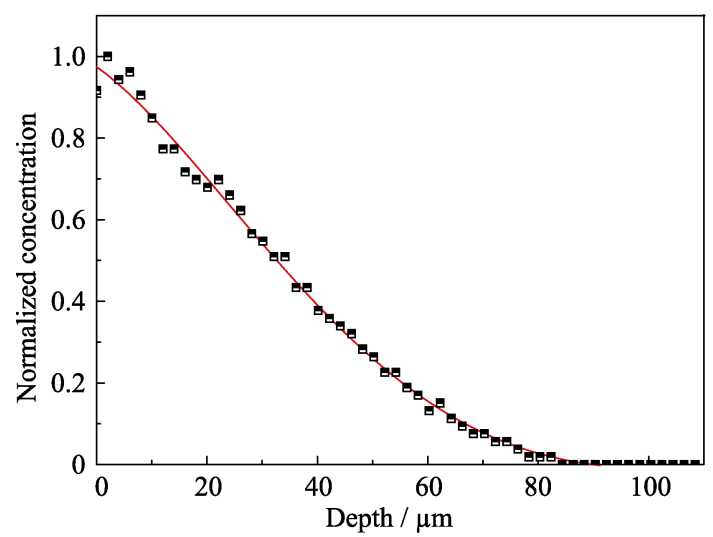

Fig. 2 The $\mathrm{K}^{+}$profile of glass subjected to the first-step ion exchange (immersed in Salt 1 at $450^{\circ} \mathrm{C}$ for $42 \mathrm{~h}$ )
As for the boundary condition of the numerical simulation, it is necessary to measure the corresponding surface $\mathrm{K}^{+}$concentration of the samples. The surface concentrations are dependent on parameters like temperature, time and the salt compositions, etc. It has been proved that the surface concentrations keep constant once the dynamic diffusion balance is established ${ }^{[24]}$. The surface potassium concentrations of the samples P0, D1 and D2 were $0,4.6$ at $\%$ and 3.413 at $\%$, respectively. The surface concentration was detected by EDS and the results were obtained by averaging the values of random three points on each sample. To simulate the second-step ion-exchange of the samples P1, P2, P3 and P4, the surface $\mathrm{K}^{+}$ concentration of sample D2, which was only subjected to the first-step ion exchange, was taken as the boundary condition. The value was also normalized in accordance with the numerical setting of the initial condition.

$$
C_{1}=C_{s}\left(D_{1}\right)=0.742
$$

\subsection{Diffusion coefficients}

The diffusion coefficients were determined by the fitting lines of the diffusion equation. Provided that the diffusion coefficients are independent of $\mathrm{K}^{+}$concentration, the $\mathrm{K}^{+}$profile can be theoretically described as ${ }^{[25]}$.

$$
\frac{C_{\mathrm{i}}-C(x, t)}{C_{\mathrm{s}}-C_{\mathrm{i}}}=\operatorname{erf}\left(\frac{x}{2 \sqrt{D t}}\right)
$$

In this instance, it is assumed that the diffusion model in 'semi-infinite long rods' applies to the diffusion process. Here $C_{\mathrm{s}}$ and $C_{\mathrm{i}}$ are termed as the surface $\mathrm{K}^{+}$concentration of the samples immersed in the molten salt and the internal concentration of the untreated glass respectively. Since $C_{\mathrm{i}}=0$, the equation can be simplified as:

$$
\frac{C(x, t)}{C_{\mathrm{s}}}=1-\operatorname{erf}\left(\frac{x}{2 \sqrt{D t}}\right)
$$

Here the left term indicates the normalized value of the $\mathrm{K}^{+}$concentration profile.

The $\mathrm{K}^{+}$profiles of glass ion-exchanged at temperature $350^{\circ} \mathrm{C}(12 \mathrm{~h}), 400^{\circ} \mathrm{C}(12 \mathrm{~h}), 450^{\circ} \mathrm{C}$ (42 h) were plotted on Fig. 3. As shown, diffusion equation fittings are conducted respectively so as to calculate the diffusion coefficients. According to Arrhenius law, the activation energy was calculated by linear fitting of the data in Table 2 .

$$
\begin{gathered}
D=D_{0} \exp \left(-\frac{E_{a}}{\mathrm{RT}}\right) \\
\ln D=-\frac{E_{a}}{\mathrm{R}} \cdot \frac{1}{T}+\ln D_{0} \\
E_{a}=117.97 \mathrm{~kJ} / \mathrm{mol}, D_{0}=6.9961 \times 10^{-6} \mathrm{~m}^{2} / \mathrm{s}
\end{gathered}
$$

The diffusion coefficients agree with the previous measurements (in the range of $10^{-16}-10^{-15} \mathrm{~m}^{2} / \mathrm{s}$ ) ${ }^{[20,26]}$. The activation energy shows a good agreement with the results given by Ref. [20]: $95.4 \mathrm{~kJ} / \mathrm{mol}$ and $145 \mathrm{~kJ} / \mathrm{mol}$. 
Diffusion coefficients as a function of $\mathrm{K}^{+}$concentrations were calculated by Boltzmann-Matano method ${ }^{[27]}$ :

$$
D(C)=-\frac{1}{2 t}\left(\frac{\mathrm{d} x}{\mathrm{~d} c}\right)_{c=C} \int_{0}^{C} x \mathrm{~d} c
$$

The calculating result (Fig. 4) shows that the diffusion coefficient expresses a monotonically increasing law. For the value assignment of the simulation, the diffusion coefficient of different concentration was also fitted by a 5-order polynomial.

$$
\begin{aligned}
D(C)= & 0.01285+2.55171 x-15.17208 x^{2}+45.47714 x^{3} \\
& -61.31302 x^{4}+30.25434 x^{5}
\end{aligned}
$$

\section{$2.3 \mathrm{~K}^{+}$concentration profile of the samples after the second-step ion exchange}

In the current study, $\Delta x$ and $\Delta t$ were set as $0.1 \mu \mathrm{m}$ and 0.5 s respectively. $C_{\mathrm{s}}$ and $C_{\mathrm{i}}$ were defined as 0.742 and 0 . As for the time and domain range, $L$ was set as $120 \mu \mathrm{m}$

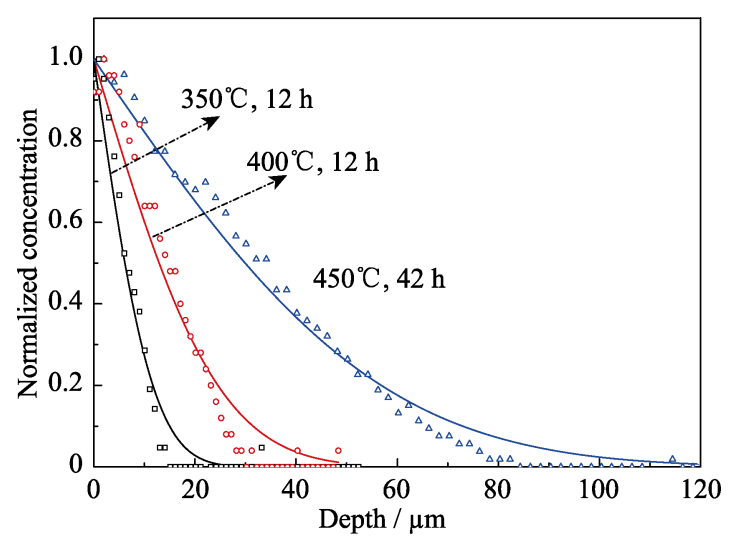

Fig. $3 \mathrm{~K}^{+}$concentration profiles of the sample P1, D1, D2 and the Boltzmann fittings

Table 2 Diffusion coefficients at $450^{\circ} \mathrm{C}, 400^{\circ} \mathrm{C}$ and $350^{\circ} \mathrm{C}$

\begin{tabular}{cccc}
\hline Temperature $/{ }^{\circ} \mathrm{C}$ & 450 & 400 & 350 \\
\hline $\mathrm{D} /\left(\mathrm{m}^{2} \cdot \mathrm{s}^{-1}\right)$ & $2.27 \times 10^{-14}$ & $4.25 \times 10^{-15}$ & $9.63 \times 10^{-16}$ \\
\hline
\end{tabular}

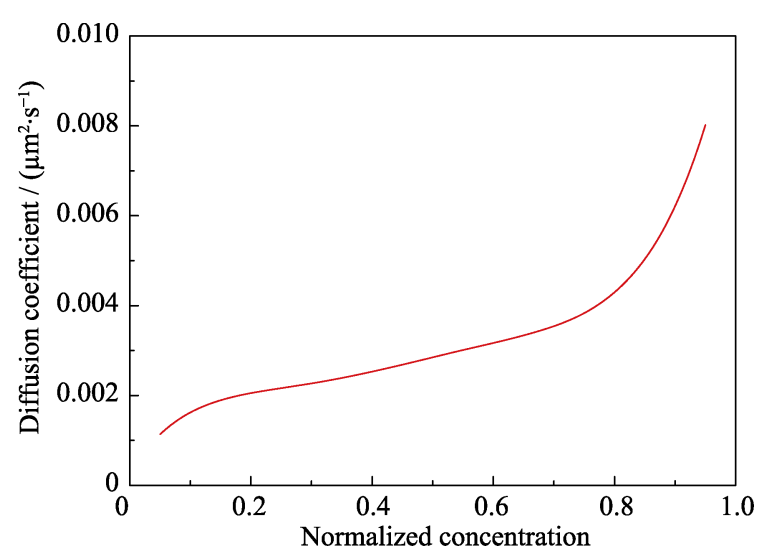

Fig. 4 Diffusion coefficients of different $\mathrm{K}^{+}$concentration at $400^{\circ} \mathrm{C}$ which entirely covered the diffusion depth $(\sim 90 \mu \mathrm{m})$, and $t$ was set as $15 \mathrm{~min}, 30 \mathrm{~min}, 1 \mathrm{~h}$ and $2 \mathrm{~h}$ respectively corresponding to the experimental treatment time. The initial condition and boundary condition can be expressed as follows:

Initial condition:

$$
\begin{aligned}
& i=0, \\
& 0 \leqslant j \leqslant 240, C_{0, j}=F(j) .
\end{aligned}
$$

where $F(j)$ represents the potassium concentration at the $j$-th site.

Boundary condition:

$$
\begin{aligned}
& i>0, \\
& j=0, C_{i, 1}=0.7414 .
\end{aligned}
$$

The following calculations were based on the constant $\mathrm{D}$ and the $\mathrm{D}$ as a function of $\mathrm{K}^{+}$concentration. The simulation and measurement results of various second- step processing time are presented on Fig. 5(a)-(d). As shown, the experimentally measured $\mathrm{K}^{+}$profile shows a good agreement with the calculation profile. As the processing time increases, the total content of $\mathrm{K}^{+}$and the maximum concentration within the subsurface area decreases gradually, and the locations of the maximum value are shifted inside as expected. However, with time lasting, the moving speeds slow down. Taking the calculation results based on constant $D$ for example, it takes only 15 min to shift the peak location from surface to $5.3 \mu \mathrm{m}$ depth while it takes $1 \mathrm{~h}$ to push it $0.8 \mu \mathrm{m}$ ahead from $7.8 \mu \mathrm{m}(1 \mathrm{~h})$ to $8.5 \mu \mathrm{m}(2 \mathrm{~h})$. Besides, the overall gradients express a declining law which is a reasonable fit with the diffusion process. The $\mathrm{K}^{+}$profiles of the samples P1, P2, and P4 show value plateaus whose location reasonably match the calculating results.

\subsection{Mechanical properties of the samples}

As shown in Table 3 and Fig. 6, the strength of any of the ion-exchanged specimens is considerably higher relative to the untreated specimens whose average strength is 100.32 MPa with Weibull modulus only 8.38.

Besides, samples D1, P1, P2 and P3, have nearly the same bending strength while the strength of $\mathrm{P} 4$ drops significantly. On the whole, the strength of the samples is positively related to the total amount of the $\mathrm{K}^{+}$and the maximum $\mathrm{K}^{+}$value which is given by the FDTD simulation results. The strength variability of $\mathrm{P} 1$ is apparently higher than the others, which can be explained that the maximum stress location is not deep enough to obstacle the surface cracks. As expected, the extent of the strength variability depends significantly on the gradients of potassium profile within the subsurface area of the ESP glass. Thus, an index that features the general gradients of $\mathrm{K}^{+}$concentration profile is defined: the slopes between the starting points and the peak points. 

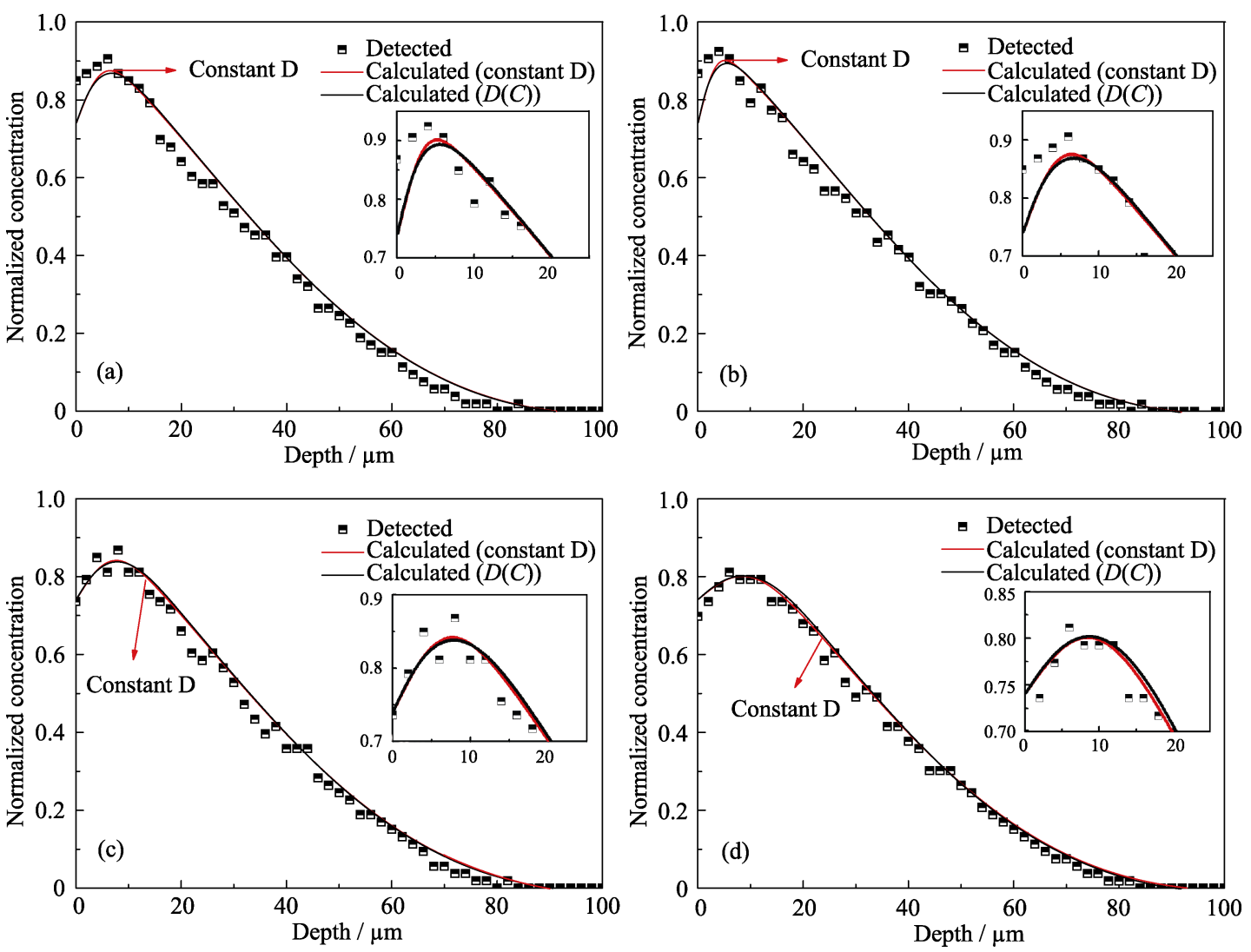

Fig. 5 Measured and calculated $\mathrm{K}^{+}$profiles in two-step ion-exchanged glass with different processing time of the second step (a) $15 \mathrm{~min}$; (b) $30 \mathrm{~min}$; (c) $1 \mathrm{~h}$; (d) $2 \mathrm{~h}$

Table 3 The relation between peak value, general gradient $\mathrm{g}$ (numerical simulation results) and strength property of the ESP glass

\begin{tabular}{|c|c|c|c|c|c|}
\hline \multirow{2}{*}{ Code } & \multicolumn{2}{|c|}{ Simulation result ${ }^{{ }^{*} 1}$} & \multirow{2}{*}{ Bend strength (16 pieces) } & \multirow{2}{*}{ Variation coefficient ${ }^{* 2}$} & \multirow{2}{*}{ Weibull modulus } \\
\hline & Peak value & $g / \mu m^{-1}$ & & & \\
\hline P0 & - & - & $100.32 \mathrm{MPa}$ & $18.0 \%$ & 8.38 \\
\hline D1 & - & - & $471.28 \mathrm{MPa}$ & $5.28 \%$ & 22.98 \\
\hline $\mathrm{P} 1$ & 0.90129 & 0.031292 & 469.16 МРa & $4.05 \%$ & 28.34 \\
\hline P2 & 0.86847 & 0.019208 & 468.88 МРa & $2.08 \%$ & 54.51 \\
\hline P3 & 0.83794 & 0.012338 & $460.61 \mathrm{MPa}$ & $2.55 \%$ & 45.43 \\
\hline P4 & 0.80203 & 0.007056 & $430.86 \mathrm{MPa}$ & $2.74 \%$ & 42.32 \\
\hline
\end{tabular}

*1: Here shows only the calculation results of the simulation based on constant $D$; *2: Variation coefficient is defined as the ratio of the standard deviation to the mean.

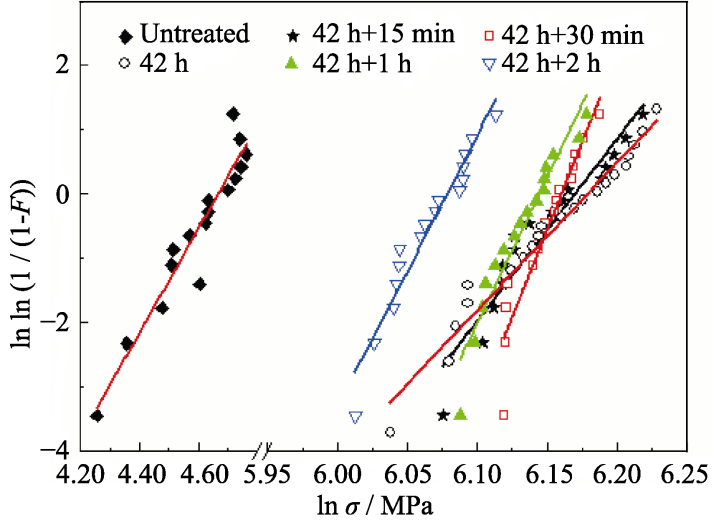

Fig. 6 Failure probability, $F$, as a function of the applied stress. Weibull modulus of the strength are corresponding slopes of the fitting lines

$$
g=\frac{C_{\mathrm{p}}-C_{\mathrm{s}}}{x_{\mathrm{p}}-x_{\mathrm{s}}}
$$

It has been theoretically proved that the gradients of the stress play a vital role in the strength stability of ESP glass. As shown in Table 3, sample P2 has the optimal performance of strength stability, because the stress peak location is deep enough and the overall concentration gradient is steep enough to obstacle the expansion of the surface cracks. Therefore, the strength of the glass is not sensitive to the original cracks and crack-like flaws which are inadvertently introduced during processing and surface machining. As the processing time of the second step increases, the Weibull modulus declines significantly. 


\section{Conclusion}

In this study, FDTD method was introduced to predict the $\mathrm{K}^{+}$profile at various conditions in the ESP glass. Based on the above analysis, the following conclusions were obtained.

The reasonable agreement between the calculation and measurement results proves the validity of FDTD method. Therefore, the ion profile can be suitably controlled by changing several parameters, and it makes significance to produce ESP glass with high strength and high Weibull modular.

The strength of ESP glass is positively related to the total amount and the maximum value of the potassium ion. However, it is necessary to reconcile the gradient and the peak value of the potassium ion profile. In this regard, $0.5 \mathrm{~h}$, the time of the second step process, is proved to be suitable to obtain high-quality ESP glass. By this treatment, ESP glass with strength of $468.88 \mathrm{MPa}$ and Weibull modular of 54.51 was prepared.

\section{Reference}

[1] LAWN B R. Fracture of Brittle Solids. Cambridge, UK: Cambridge Univ. Press, 1993.

[2] GRIFFITH A A. The phenomona of rupture and flow in solid. Phil. Trans. R. Soc. Lond. A, 1920, 221(4): 163-190.

[3] WEIBULL W. A statistical distribution function of wide applicability. J. Appl. Mech.-Trans. ASME, 1951, 18(3): 293-297.

[4] DENG B, JIANG D. Determination of the weibull parameters from the mean value and the coefficient of variation of the measured strength for brittle ceramics. Journal of Advanced Ceramics, 2017, 6(2): 149-156.

[5] RAO M P, SANCHEZ-HERENCIA A J, BELTZ G E, et al. Laminar ceramics that exhibit a threshold strength. Science, 1999, 286(5437): 102-105.

[6] FILLERY S P, LANGE F F. Ion-exchanged glass laminates that exhibit a threshold strength. J. Am. Ceram. Soc., 2007, 90(8): 2502-2509.

[7] FAIR G E, LANGE F F. Ceramic composites with three-dimensional architectures designed to produce a threshold strength - I. Processing. J. Am. Ceram. Soc., 2005, 88(5): 1158-1164.

[8] FAIR G E, HE M Y, MCMEEKING R M, et, al. Ceramic composites with three-dimensional architectures designed to produce a threshold strength - II. Mechanical observations. J. Am. Ceram.
Soc., 2005, 88(7): 1879-1885.

[9] KARLSSON S, JONSON B, STALHANDSKE C. The technology of chemical glass strengthening - a review. Glass Technol.-Eur. J. Glass Sci. Technol. Part A, 2010, 51: 41-54.

[10] VARSHNEYA A K. Chemical strengthening of glass: lessons learned and yet to be learned. Int. J. Appl. Glass Sci., 2010, 1: 131-142.

[11] TANDON R, GREEN D J. Crack stability and t-curves due to macroscopic residual compressive stress profiles. J. Am. Ceram. Soc., 1991, 74(8): 1981-1986.

[12] GREEN D J, TANDON R, SGLAVO V M. Crack arrest and multiple cracking in class through the use of designed residual stress profiles. Science, 1999, 283(5406): 1295-1297.

[13] SGLAVO V M, LARENTIS L, GREEN D J. Flaw-insensitive ion-exchanged glass: I, Theoretical aspects. J. Am. Ceram. Soc., 2001, 84(8): 1827-1831.

[14] SGLAVO V M, GREEN D J. Flaw-insensitive ion-exchanged glass: II, Production and mechanical performance. J. Am. Ceram. Soc., 2001, 84(8): 1832-1838.

[15] GREEN D J. Critical parameters in the processing of engineered stress profile glasses. J. Non-Cryst. Solids, 2003, 316(1): 35-41.

[16] ABRAMS M B, GREEN D J. Prediction of crack propagation and fracture in residually stressed glass as a function of the stress profile and flaw size distribution. J. Eur. Ceram. Soc., 2006, 26(13): 2677-2684.

[17] COOK R F, CLARKE D R. Fracture stability, r-curves and strength variability. Acta Metall., 1988, 36(3): 555-562.

[18] SHETTY D K, WANG J S. Crack stability and strength distribution of ceramics that exhibit rising crack-growth-resistance (r-curve) behavior. J. Am. Ceram. Soc., 1989, 72(7): 1158-1162.

[19] VARSHNEYA A K. Mechanical model to simulate buildup and relaxation of stress during glass chemical strengthening. $J$. Non-Cryst. Solids, 2016, 433: 28-30.

[20] SHEN J W, GREEN D J. Prediction of stress profiles in ion exchanged glasses. J. Non-Cryst. Solids, 2004, 344(1/2): 79-87.

[21] VARSHNEYA A K, OLSON G A, KRESKI P K, et, al. Buildup and relaxation of stress in chemically strengthened glass. $J$. Non-Cryst. Solids, 2015, 427: 91-97.

[22] SHIDFAR A, AZARY H. An inverse problem for a nonlinear diffusion equation. Nonlinear Anal.-Theory Methods Appl., 1997, 28(4): 589-593.

[23] FATULLAYEV A. Determination of unknown coefficient in nonlinear diffusion equation. Nonlinear Anal.-Theory Methods Appl., 2001, 44(3): 337-344.

[24] SHEN J W, GREEN D J, PANTANO C G. Control of concentration profiles in two step ion exchanged glasses. Phys. Chem. Glasses, 2003, 44(4): 284-292.

[25] MEHRER H. Diffusion in Solids: Fundamentals, Methods, Materials, Diffusion-controlled Processes. Berlin Heidelberg: Springer-Verlag, 2007.

[26] LI X Y, JIANG L B, WANG Y, et al. Correlation between $\mathrm{K}^{+}-\mathrm{Na}^{+}$ diffusion coefficient and flexural strength of chemically tempered aluminosilicate glass. J. Non-Cryst. Solids, 2017, 471: 72-81.

[27] MATANO C. On the relation between diffusion-coefficients and concentrations of solid metals. Japanese Journal of Physics, 1933, 8: $109-113$.

\title{
基于时域有限差分法的 ESP 玻璃的钾离子浓度分布的模拟
}

\author{
郑国源 ${ }^{1,2}$, 李家成 ${ }^{1}$, 宋力昕 ${ }^{1}$, 张 涛 $^{1}$ \\ (1. 中国科学院 上海硅酸盐研究所, 中国科学院特种无机涂层重点实验室, 上海 200050; 2. 中国科学院大学, 北 \\ 京 100049)
}

摘 要: 由于特殊的交换离子浓度分布, 工程应力分布玻璃(ESP玻璃)的强度呈现集中分布的特性。为了预测其钾离子 浓度的分布, 运用了时域有限差分法对其扩散过程进行数值模拟。该模拟是基于测量的扩散系数、玻璃表面浓度 以及第一步交换后的钾离子浓度分布进行的。模拟计算的结果与使用能谱仪测量的实验结果相吻合。基于模拟计 算的结果, 讨论了 ESP 玻璃的强度与钾离子浓度分布的关系。

关 键 词: 离子交换; 工程应力分布玻璃（ESP 玻璃）；时域有限差分法; 强度

中图分类号: TQ174 文献标识码: A 